\title{
Predicting Long-term Functional Outcome of Stroke Using Multivariate Analysis
}

\author{
SATOSHI SUGIMOTO ${ }^{1)}$, TADASHI KANDA ${ }^{2)}$, FUMIHIKo SAKAI ${ }^{3)}$ \\ 1) Geriatric Health and Care Service Facility Hidakanosato: \\ 96-1 Hidaka-shi, Saitama 350-1254, Japan. \\ TEL +81 42-982-3333 FAX +8142-982-0637 E-mail: rihabili@oregano.ocn.ne.jp \\ ${ }^{2)}$ Faculty of Rehabilitation, School of Allied Health Sciences, Kitasato University \\ ${ }^{3)}$ Department of Neurology, School of Medicine, Kitasato University
}

J. Phys. Ther. Sci.

16: $129-135,2004$

\begin{abstract}
The purpose of the present study was to investigate long-term prognosis of patients with stroke and to identify predictive factors for functional outcome. Subjects were consecutively hospitalized 1,056 patients with stroke due to unilateral hemispheric lesions at the Department of Neurology, Kitasato University Hospital from 1986 to 1997 . One hundred and eighty-three patients died during hospital stay. The remaining 873 surviving patients were followed for 5 years after onset of stroke. Locomotive function (mobility status) of surviving patients was assessed by questionnaires mailed at 2 years and at 5 years after stroke. Outcome of locomotive function was classified into the following 5 categories: normal, walk alone, walk with device, using wheelchair, and bedridden. The following factors were tested by means of multiple regression analysis: age, sex, level of consciousness, location and size of lesion, history of previous stroke and 2 major risk factors for stroke (hypertension and diabetes mellitus). The results of multivariate analysis revealed that in patients with intracerebral hemorrhage, although level of consciousness on admission was the strongest predictor at discharge, locomotive function at discharge was the most important predictor at 2 years and at 5 years after stroke. Moreover, age was more strongly related to functional outcome than level of consciousness at 2 years and at 5 years after stroke. This trend was also found in patients with cerebral infarction. Multivariate analysis revealed that a linear combination of these predictors accounted for about $50 \%$ of the variance in the estimate of functional outcome at 2 years and at 5 years after stroke. The results of the present study suggest that the long-term outcome of stroke patients is more deeply influenced by unidentified factors which may not be present during the hospital stay.
\end{abstract}

Key words: Stroke, Long-term outcome, Predictive factors

(This article was submitted Jun. 28, 2004, and was accepted Sep. 27, 2004)

\section{INTRODUCTION}

Numerous studies have reported the outcome of stroke patients. However, many studies ${ }^{1-10)}$ have only considered the outcome during the first year after stroke. Furthermore, the studies that have analyzed the long-term outcome ${ }^{11-19)}$ focused on mortality. Recent studies ${ }^{1-9,20,21)}$ have reported about predictive factors for outcome using multivariate analysis. However, they have not clarified the relationship between these factors and the outcome over a range of time periods after stroke. It is important for physical therapists to predict locomotive function after discharge in order to decide what therapists should do for patients during hospitalization. The purpose of this study was to investigate the long-term functional outcome of stroke patients and to identify predictive factors for locomotive function over time. 
Table 1. Characteristics of patients on admission

\begin{tabular}{|c|c|c|c|c|c|c|c|c|c|c|}
\hline & \multicolumn{2}{|c|}{$\begin{array}{l}\text { all patients } \\
(n=1056)\end{array}$} & \multicolumn{2}{|c|}{$\begin{array}{l}\text { intracerebral } \\
\text { hemorrhage } \\
\quad(n=498)\end{array}$} & \multicolumn{2}{|c|}{$\begin{array}{c}\text { cardiogenic } \\
\text { cerebral embolism } \\
\qquad(\mathrm{n}=202)\end{array}$} & \multicolumn{2}{|c|}{$\begin{array}{l}\text { thrombotic } \\
\text { cerebral infarction } \\
\qquad(\mathrm{n}=211)\end{array}$} & \multicolumn{2}{|c|}{$\begin{array}{c}\text { lacunar } \\
\text { infarction } \\
(\mathrm{n}=145)\end{array}$} \\
\hline & $\mathrm{n}$ & $\%$ & $\mathrm{n}$ & $\%$ & $\mathrm{n}$ & $\%$ & $\mathrm{n}$ & $\%$ & $\mathrm{n}$ & $\%$ \\
\hline \multicolumn{11}{|l|}{$\operatorname{sex}$} \\
\hline male & 654 & 61.9 & 298 & 59.8 & 106 & 52.4 & 151 & 71.5 & 99 & 68.2 \\
\hline \multicolumn{11}{|l|}{ level of consciousness } \\
\hline alertness & 541 & 51.2 & 177 & 35.5 & 81 & 40.0 & 143 & 67.7 & 140 & 96.5 \\
\hline somnolence & 273 & 25.8 & 140 & 28.1 & 72 & 35.6 & 56 & 26.5 & 5 & 3.5 \\
\hline stupor & 132 & 12.5 & 78 & 15.6 & 42 & 20.7 & 12 & 5.6 & 0 & 0.0 \\
\hline coma & 110 & 10.4 & 103 & 20.6 & 7 & 3.4 & 0 & 0.0 & 0 & 0.0 \\
\hline \multicolumn{11}{|l|}{ side of lesion } \\
\hline $\begin{array}{l}\text { right } \\
\text { size of lesion }\end{array}$ & 539 & 51.0 & 250 & 50.2 & \multicolumn{5}{|c|}{ size of lesion } & 51.7 \\
\hline small & 261 & 24.7 & 95 & 19.0 & 7 & 3.4 & 14 & 6.6 & 145 & 100.0 \\
\hline middle & 506 & 47.9 & 256 & 51.4 & 94 & 46.5 & 156 & 73.9 & 0 & 0.0 \\
\hline large & 289 & 27.3 & 147 & 29.5 & 101 & 50.0 & 41 & 19.4 & 0 & 0.0 \\
\hline \multicolumn{11}{|l|}{ history of stroke } \\
\hline \multicolumn{11}{|l|}{ hypertension } \\
\hline present & 738 & 69.9 & 408 & 82.0 & 88 & 43.6 & 136 & 64.5 & 106 & 73.2 \\
\hline \multicolumn{11}{|l|}{ diabetes mellitus } \\
\hline present & 194 & 18.4 & 67 & 13.5 & 28 & 13.9 & 68 & 32.3 & 31 & 21.4 \\
\hline \multicolumn{11}{|l|}{ age* } \\
\hline (years) & \multicolumn{2}{|c|}{$63.1 \pm 12.5$} & \multicolumn{2}{|c|}{$60.8 \pm 12.0$} & \multicolumn{2}{|c|}{$69.2 \pm 11.2$} & \multicolumn{2}{|c|}{$63.5 \pm 13.6$} & \multicolumn{2}{|c|}{$62.3 \pm 11.5$} \\
\hline
\end{tabular}

*mean \pm standard deviation.

\section{METHODS}

The subjects were 1,056 consecutive stroke patients (402 women and 654 men) with unilateral cerebral hemispheric lesions, who were admitted to the Department of Neurology, Kitasato University Hospital between January 1986 and August 1997. The patients were admitted within 3 days of the onset of stroke. The number of patients in the subtypes of stroke was as follows: intracerebral hemorrhage, 498; cardiogenic cerebral embolism, 202; thrombotic cerebral infarction, 211; and lacunar infarction, 145. The characteristics of the patients are summarized in Table 1. A total of 183 patients died during hospital stay. The functional outcome of 873 patients who survived was assessed by a mailed questionnaire at 2 years and at 5 years after their strokes. Informed consent was obtained after we explained the nature of the investigation, using a letter mailed with the questionnaire.

\section{DEFINITIONS AND BASELINE MEASURES}

The following predictors for analysis of functional outcome were used in this study: age, sex, level of consciousness on admission, side and size of cerebral hemispheric lesion, history of previous stroke, and 2 major risk factors for stroke (hypertension and diabetes mellitus). The scales used for these predictors are shown in Table 2. Level of consciousness was categorized into 4 grades (alertness, somnolence, stupor, coma). Size of lesion, which was estimated by findings of computed tomography scan or magnetic resonance imaging, was divided into 3 scales: small $(<20 \mathrm{~mm}$ in diameter), middle ( $>20 \mathrm{~mm}$ in diameter and smaller than the lobe) and large (extended over the lobe). Functional outcome was classified by locomotive function into the following 5 categories: normal, walk alone, walk with device, using a wheelchair, and bedridden, as shown in Table 3.

\section{STATISTICAL ANALYSIS}

All analyses were performed using SPSS ver11.5J. Univariate analysis was performed to correlate functional outcome at discharge, at 2 years or at 5 years after stroke with each predictor using 
Table 2. Scales used for predictors

\begin{tabular}{ll}
\hline \multicolumn{1}{c}{ predictors } & code \\
\hline sex & $1=$ male \\
& $2=$ female \\
1 level of consciousness & $=$ alertness \\
2 & $=$ somnolence \\
3 & $=$ stupor \\
4 & $=$ coma \\
& $1=$ right \\
side of lesion & $2=$ left \\
& $1=$ small \\
size of lesion* & $=$ middle \\
& $3=$ large \\
& $0=$ none \\
history of stroke & $1=$ present \\
hypertension & $0=$ none \\
& $1=$ present \\
diabetes mellitus & $0=$ none \\
1 & $=$ present \\
types of infarction & $0=$ lacunar \\
& $1=$ thrombotic \\
2 & $=$ cardiogenic \\
&
\end{tabular}

*small, $<20 \mathrm{~mm}$ in diameter. middle, $>20$ $\mathrm{mm}$ in diameter and smaller than the lobe. large, extended over the lobe.

Mann-Whitney's U test or the Kruskal-Wallis test.

Stepwise multiple regression models were used for defining predictors of functional outcome at the time of discharge, at 2 years or at 5 years after stroke. All the patients were divided into 2 groups (intracerebral hemorrhage, and cerebral infarction) in this analysis because of the small number of patients in each type of cerebral infarction. Functional outcome at 2 years and at 5 years after the stroke were investigated by multivariate analysis models using locomotive function at discharge as a variable in addition to the other predictors. The level of significance was set at $P<0.05$.
Table 3. A scale for evaluating locomotive function

\begin{tabular}{cll}
\hline code & grade & \multicolumn{1}{c}{ evaluation } \\
\hline 1 & normal & walk normally \\
2 & walk alone & walk independently without device \\
3 & walk with device & walk with cane or/and brace \\
4 & wheelchair & unable to walk, require a \\
& & wheelchair in locomotion \\
5 & bedridden & unable to sit up \\
\hline
\end{tabular}

\section{RESULTS}

Seven-hundred and fifty-one patients completed the questionnaire at 2 years after stroke, and 516 patients were followed for 5 years after stroke. Table 4 shows the cumulative mortality rates during the 5 years after stroke by subtypes of stroke. A total of 366 patients died within 5 years of stroke. One hundred and eighty three patients died during hospital stay and 110 of the patients who survived the acute stage died within 2 years. In addition, 73 of the patients who survived for 2 years after stroke died within 5 years. The mortality rate of the patients with cardiogenic cerebral embolism was the highest among the 4 types at any period after stroke. Table 5 shows functional outcome at discharge, at 2 years and at 5 years after stroke. At the time of discharge, 475 patients $(44.9 \%)$ were able to walk without a device (i.e. code 1 and 2). At 2 years and 5 years after stroke 403 patients $(53.5 \%)$ and 285 patients $(55.1 \%)$, respectively, walked without a device. Although patients with lacunar infarction had the best locomotive function of the 4 types of stroke at the time of discharge, the percentage of patients with good locomotive function at 5 years after stroke was similar among all 4 types.

Table 6 shows the relationship between locomotive function at the time of discharge and locomotive function at 2 years and at 5 years after

Table 4. Comparsions of cumulative mortality rates during 5 years after stroke

\begin{tabular}{|c|c|c|c|c|c|c|c|c|c|c|}
\hline & \multicolumn{2}{|c|}{ all patients } & \multicolumn{2}{|c|}{$\begin{array}{l}\text { intracerebral } \\
\text { hemorrhage }\end{array}$} & \multicolumn{2}{|c|}{$\begin{array}{c}\text { cardiogenic } \\
\text { cerebral embolism }\end{array}$} & \multicolumn{2}{|c|}{$\begin{array}{c}\text { thrombotic } \\
\text { cerebral infarction }\end{array}$} & \multicolumn{2}{|c|}{$\begin{array}{l}\text { lacunar } \\
\text { infarction }\end{array}$} \\
\hline & $\mathrm{n}$ & $\%$ & $\mathrm{n}$ & $\%$ & $\mathrm{n}$ & $\%$ & $\mathrm{n}$ & $\%$ & $\mathrm{n}$ & $\%$ \\
\hline at discharge & 183 & 17.3 & 114 & 22.8 & 52 & 25.7 & 16 & 7.5 & 1 & 0.6 \\
\hline at 2 years & 293 & 31.3 & 150 & 33.4 & 94 & 53.4 & 38 & 20.4 & 11 & 8.8 \\
\hline at 5 years & 366 & 45.2 & 176 & 45.8 & 107 & 66.8 & 58 & 36.7 & 25 & 23.3 \\
\hline
\end{tabular}


Table 5. Comparisons of locomotive function at discharge, 2 years and 5 years after stroke

\begin{tabular}{|c|c|c|c|c|c|c|c|c|c|c|}
\hline & \multicolumn{2}{|c|}{ all patients } & \multicolumn{2}{|c|}{$\begin{array}{l}\text { intracerebral } \\
\text { hemorrhage }\end{array}$} & \multicolumn{2}{|c|}{$\begin{array}{c}\text { cardiogenic } \\
\text { cerebral embolism }\end{array}$} & \multicolumn{2}{|c|}{$\begin{array}{l}\text { thrombotic } \\
\text { cerebral infarction }\end{array}$} & \multicolumn{2}{|c|}{$\begin{array}{l}\text { lacunar } \\
\text { infarction }\end{array}$} \\
\hline & $\mathrm{n}$ & $\%$ & $\mathrm{n}$ & $\%$ & $\mathrm{n}$ & $\%$ & $\mathrm{n}$ & $\%$ & $\mathrm{n}$ & $\%$ \\
\hline \multicolumn{11}{|l|}{ at discharge } \\
\hline normal & 147 & 13.9 & 68 & 13.6 & 16 & 7.9 & 25 & 11.8 & 38 & 26.2 \\
\hline walk alone & 328 & 31.0 & 113 & 22.6 & 57 & 28.2 & 84 & 39.8 & 74 & 51.0 \\
\hline walk with device & 121 & 11.4 & 61 & 12.2 & 7 & 3.4 & 29 & 13.7 & 24 & 16.5 \\
\hline wheelchair & 167 & 15.8 & 90 & 18.0 & 31 & 15.3 & 38 & 18.0 & 8 & 5.5 \\
\hline bedridden & 110 & 10.4 & 52 & 10.4 & 39 & 19.3 & 19 & 9.0 & 0 & 0.0 \\
\hline dead & 183 & 17.3 & 114 & 22.8 & 52 & 25.7 & 16 & 7.5 & 1 & 0.6 \\
\hline total & 1056 & & 498 & & 202 & & 211 & & 145 & \\
\hline \multicolumn{11}{|l|}{ at 2 years } \\
\hline normal & 280 & 37.2 & 121 & 36.2 & 38 & 30.6 & 56 & 32.9 & 65 & 52.8 \\
\hline walk alone & 123 & 16.3 & 57 & 17.0 & 13 & 10.4 & 35 & 20.5 & 18 & 14.6 \\
\hline walk with device & 132 & 17.5 & 67 & 20.0 & 12 & 9.6 & 28 & 16.4 & 25 & 20.3 \\
\hline wheelchair & 62 & 8.2 & 32 & 9.5 & 9 & 7.2 & 17 & 10.0 & 4 & 3.2 \\
\hline bedridden & 44 & 5.8 & 21 & 6.2 & 10 & 8.0 & 12 & 7.0 & 1 & 0.8 \\
\hline dead & 110 & 14.6 & 36 & 10.7 & 42 & 33.8 & 22 & 12.9 & 10 & 8.1 \\
\hline total & 751 & & 334 & & 124 & & 170 & & 123 & \\
\hline \multicolumn{11}{|l|}{ at 5 years } \\
\hline normal & 202 & 39.1 & 81 & 34.6 & 26 & 39.3 & 44 & 36.6 & 51 & 53.1 \\
\hline walk alone & 83 & 16.0 & 45 & 19.2 & 9 & 13.6 & 18 & 15.0 & 11 & 11.4 \\
\hline walk with device & 100 & 19.3 & 52 & 22.2 & 10 & 15.1 & 23 & 19.1 & 15 & 15.6 \\
\hline wheelchair & 41 & 7.9 & 23 & 9.8 & 3 & 4.5 & 11 & 9.1 & 4 & 4.1 \\
\hline bedridden & 17 & 3.2 & 7 & 2.9 & 5 & 7.5 & 4 & 3.3 & 1 & 1.0 \\
\hline dead & 73 & 14.1 & 26 & 11.1 & 13 & 19.6 & 20 & 16.6 & 14 & 14.5 \\
\hline total & 516 & & 234 & & 66 & & 120 & & 96 & \\
\hline
\end{tabular}

Table 6. Relationship between locomotive function at discharge, 2 and 5 years after stroke

\begin{tabular}{|c|c|c|c|c|c|c|c|c|c|c|c|c|}
\hline & \multicolumn{12}{|c|}{ at 2 years $(n=751)$} \\
\hline & \multicolumn{2}{|c|}{ normal } & \multicolumn{2}{|c|}{ walk alone } & \multicolumn{2}{|c|}{ walk with device } & \multicolumn{2}{|c|}{ wheelchair } & \multicolumn{2}{|c|}{ bedridden } & \multicolumn{2}{|c|}{ dead } \\
\hline & $\mathrm{n}$ & $\%$ & $\mathrm{n}$ & $\%$ & $\mathrm{n}$ & $\%$ & $\mathrm{n}$ & $\%$ & $\mathrm{n}$ & $\%$ & $\mathrm{n}$ & $\%$ \\
\hline \multicolumn{13}{|l|}{ at discharge } \\
\hline normal & 93 & 75.6 & 11 & 8.9 & 9 & 7.3 & 1 & 0.8 & 1 & 0.8 & 8 & 6.5 \\
\hline walk alone & 159 & 54.8 & 78 & 26.8 & 19 & 6.5 & 3 & 1.0 & 6 & 2.0 & 25 & 8.6 \\
\hline walk with device & 17 & 15.3 & 20 & 18.0 & 50 & 45.0 & 10 & 9.0 & 3 & 2.7 & 11 & 9.9 \\
\hline wheelchair & 11 & 7.8 & 12 & 8.5 & 51 & 36.4 & 35 & 25.0 & 11 & 7.8 & 20 & 14.2 \\
\hline \multirow[t]{4}{*}{ bedridden } & 0 & 0.0 & 2 & 2.2 & 3 & 3.4 & 13 & 14.9 & 23 & 26.0 & 46 & 52.8 \\
\hline & \multicolumn{12}{|c|}{ at 5 years $(n=516)$} \\
\hline & \multicolumn{2}{|c|}{ normal } & \multicolumn{2}{|c|}{ walk alone } & \multicolumn{2}{|c|}{ walk with device } & \multicolumn{2}{|c|}{ wheelchair } & \multicolumn{2}{|c|}{ bedridden } & \multicolumn{2}{|c|}{ dead } \\
\hline & $\mathrm{n}$ & $\%$ & $\mathrm{n}$ & $\%$ & $\mathrm{n}$ & $\%$ & $\mathrm{n}$ & $\%$ & $\mathrm{n}$ & $\%$ & $\mathrm{n}$ & $\%$ \\
\hline \multicolumn{13}{|l|}{ at discharge } \\
\hline normal & 68 & 70.8 & 8 & 8.3 & 7 & 7.2 & 3 & 3.1 & 0 & 0.0 & 10 & 10.4 \\
\hline walk alone & 115 & 53.7 & 50 & 23.3 & 5 & 7.0 & 2 & 0.9 & 4 & 1.8 & 28 & 13.0 \\
\hline walk with device & 12 & 15.1 & 15 & 18.9 & 40 & 50.6 & 10 & 2.5 & 4 & 1.0 & 45 & 11.5 \\
\hline wheelchair & 7 & 6.9 & 10 & 9.9 & 35 & 34.6 & 25 & 24.7 & 8 & 7.9 & 16 & 15.8 \\
\hline bedridden & 0 & 0.0 & 0 & 0.0 & 3 & 11.3 & 6 & 23.0 & 5 & 19.2 & 12 & 46.1 \\
\hline
\end{tabular}


Table 7. Predictors for locomotive function by univariate analysis

\begin{tabular}{|c|c|c|c|c|c|c|c|c|c|c|c|c|}
\hline & \multicolumn{3}{|c|}{$\begin{array}{l}\text { intracerebral } \\
\text { hemorrhage }\end{array}$} & \multicolumn{3}{|c|}{$\begin{array}{c}\text { cardiogenic cerebral } \\
\text { embolism }\end{array}$} & \multicolumn{3}{|c|}{$\begin{array}{l}\text { thrombotic cerebral } \\
\text { infarction }\end{array}$} & \multicolumn{3}{|c|}{$\begin{array}{l}\text { lacunar } \\
\text { infarction }\end{array}$} \\
\hline & discharge & 2 years & 5 years & discharge & 2 years & 5 years & discharge & 2 years & 5 years & discharge & 2 years & 5 years \\
\hline age & $*$ & $* *$ & $* *$ & $*$ & $* *$ & $*$ & $\mathrm{~ns}$ & $* *$ & ns & $\mathrm{ns}$ & $* *$ & $* *$ \\
\hline sex & $*$ & $* *$ & $*$ & ns & $*$ & ns & ns & ns & ns & ns & ns & ns \\
\hline level of consciousness & s $* *$ & $* *$ & $* *$ & $* *$ & $* *$ & $* *$ & $* *$ & $* *$ & $* *$ & ns & ns & ns \\
\hline side of lesion & $\mathrm{ns}$ & $*$ & ns & $\mathrm{ns}$ & $\mathrm{ns}$ & $*$ & $\mathrm{~ns}$ & $\mathrm{~ns}$ & $\mathrm{~ns}$ & $\mathrm{~ns}$ & $*$ & $\mathrm{~ns}$ \\
\hline size of lesion & $* *$ & $* *$ & $* *$ & $* *$ & $* *$ & ns & $*$ & ns & $*$ & $(-)$ & $(-)$ & $(-)$ \\
\hline history of stroke & $\mathrm{ns}$ & $*$ & $\mathrm{~ns}$ & ns & $\mathrm{ns}$ & ns & ns & $*$ & ns & $\mathrm{ns}$ & $\mathrm{ns}$ & $\mathrm{ns}$ \\
\hline hypertension & ns & $\mathrm{ns}$ & $\mathrm{ns}$ & ns & $\mathrm{ns}$ & ns & ns & $\mathrm{ns}$ & ns & $\mathrm{ns}$ & $\mathrm{ns}$ & $*$ \\
\hline diabetes mellitus & ns & ns & ns & ns & ns & ns & ns & ns & $*$ & $\mathrm{~ns}$ & ns & ns \\
\hline
\end{tabular}

$* *: \mathrm{p}<.01, *: \mathrm{p}<.05$, ns: not significant, $(-)$ : not compared.

stroke. Fifty percent of bedridden patients at discharge died within 2 years of stroke, while $30 \%$ of patients who needed a device to walk and $50 \%$ of patients who required a wheelchair for locomotion at discharge had better locomotive function at 2 years. A similar tendency was found at 5 years after stroke.

\section{UNIVARIATE ANALYSIS}

Table 7 shows the result of the univariate analysis of predictors for locomotive function at discharge, at 2 and 5 years after stroke. In patients with intracerebral hemorrhage and cardiogenic cerebral embolism, age, level of consciousness and size of lesion were significant factors for locomotive function in the three assessment periods, except for side of lesion at 5 years after stroke of patients with cardiogenic cerebral embolism. Significant factors influencing locomotive function of patients with thrombotic cerebral infarction were similar to those for patients with intracerebral hemorrhage and cardiogenic cerebral embolism. However, age was a significant factor only at 2 years after stroke. In patients with lacunar infarction, age was a significant factor for locomotive function at 2 and 5 years.

\section{MULTIVARIATE ANALYSIS}

Table 8 shows the results of the stepwise progression model. In patients with intracerebral hemorrhage, although level of consciousness on admission was the strongest predictor at discharge, locomotive function at discharge was the most important predictor at 2 years and at 5 years after stroke. Moreover, age was more strongly related to functional outcome than level of consciousness at 2 years and at 5 years after stroke. This trend was also found for patients with cerebral infarction. Multivariate analysis revealed that a linear combination of these predictors accounted for about $50 \%$ of the variance in the estimate of functional outcome at 2 years and at 5 years after stroke.

\section{DISCUSSION}

Although level of consciousness on admission and size of lesion had an influence on locomotive function at discharge, age was more strongly related to the long-term outcome. This fact suggests that predictors for locomotive function change with time course after the onset of stroke. Daverat et al. ${ }^{2)}$ reported that early (30-day) survival was correlated with status of hemorrhage, while later (6-month) survival was correlated with age. Kojima et al. ${ }^{16)}$ concluded that the survival rate of stroke patients over 65 years old after 5 years was significantly lower than that of younger patients. Using multivariate analysis, Appelros et al. ${ }^{1)}$ reported that age was not a significant factor for 30-day fatality. In a subsequent study ${ }^{20)}$, they emphasized that age was an important factor for 1-year mortality. The results of these studies are consistent with our results that predictors for stroke outcome change with time.

Our analysis of functional outcome at 2 years or at 5 years after stroke indicated that locomotive function at the time of discharge was the most important predictive factor of long-term outcome. In other words, long-term locomotive function of stroke patients is strongly influenced by the ability 
Table 8. Multiple analysis for locomotive function

\begin{tabular}{|c|c|c|c|c|c|c|c|}
\hline \multicolumn{4}{|c|}{ intracerebral hemorrhage } & \multicolumn{4}{|c|}{ cerebral infarction } \\
\hline at discharge $(n=384)$ & & & & at discharge $(n=389)$ & & & \\
\hline & $\beta$ & SE & $\mathrm{P}$ & & $\beta$ & SE & $\mathrm{P}$ \\
\hline consciousness & .407 & .087 & $<.001$ & consciousness & .300 & .116 & $<.001$ \\
\hline size of lesion & .318 & .127 & $<.001$ & size of lesion & .203 & .087 & $<.001$ \\
\hline $\begin{array}{l}\text { history of stroke } \\
\left(\mathrm{R}^{2}=.400\right)\end{array}$ & .110 & .160 & .030 & $\begin{array}{l}\text { age } \\
\qquad\left(\mathrm{R}^{2}=.213\right)\end{array}$ & .182 & .004 & $<.001$ \\
\hline at 2 years $(n=298)$ & & & & at 2 years $(n=343)$ & & & \\
\hline & $\beta$ & SE & $\mathrm{P}$ & & $\beta$ & SE & $\mathrm{P}$ \\
\hline LF at discharge & .596 & .054 & $<.001$ & LF at discharge & .575 & .052 & $<.001$ \\
\hline age & .269 & .005 & $<.001$ & age & .242 & .004 & $<.001$ \\
\hline consciousness & .160 & .079 & .002 & consciousness & .091 & .108 & .037 \\
\hline history of stroke & .100 & .140 & .017 & & & & \\
\hline $\begin{array}{l}\text { diabetes mellitus } \\
\quad\left(\mathrm{R}^{2}=.597\right)\end{array}$ & .092 & .161 & .027 & $\left(\mathrm{R}^{2}=.482\right)$ & & & \\
\hline at 5 years $(n=208)$ & & & & at 5 years $(n=235)$ & & & \\
\hline & $\beta$ & SE & $P$ & & $\beta$ & SE & $\mathrm{P}$ \\
\hline LF at discharge & .537 & .070 & $<.001$ & LF at discharge & .579 & .061 & $<.001$ \\
\hline age & .357 & .007 & $<.001$ & age & .260 & .005 & $<.001$ \\
\hline history of stroke & .157 & .194 & .009 & consciousness & .131 & .126 & .013 \\
\hline $\begin{array}{c}\text { consciousness } \\
\left(\mathrm{R}^{2}=.475\right)\end{array}$ & .151 & .103 & .032 & $\begin{array}{l}\text { diabetes mellitus } \\
\left(\mathrm{R}^{2}=.513\right)\end{array}$ & .097 & .141 & .039 \\
\hline
\end{tabular}

Abbreviations: LF at discharge, locomotive function at discharge.

$\beta$, standardized partial regression coefficient.

$\mathrm{SE}$, standard error.

$\mathrm{R}^{2}$, multiple correlation coefficient adjusted for the degrees of freedom.

to walk during their hospitalization. Therefore, locomotive function at the time of discharge should be included as an explanatory variable for predicting long-term outcome. Additionally, we have to conduct a program for stroke patients to improve locomotive function during their hospital stay.

However, a linear combination of these predictors accounted for $50 \%$ of the variance in functional outcome at 2 years and at 5 years after stroke. Paolucci et al. ${ }^{21)}$ reported that mobility status of stroke patients had not yet stabilized at the time of discharge and post discharge treatment (PDT) was useful for further improvement. In the present study, an improvement of locomotive function was found even at 2 years after stroke in $30 \%$ of patients who needed a device to walk, and in $50 \%$ of patients who required a wheelchair at the time of discharge. This fact suggests that the long-term outcome is more deeply influenced by unidentified factors which may not be present during the hospital stay. For example, utilization of social supports or caregivers help may be one of these unidentified factors.

In conclusion, it is necessary for physical therapists to improve patients' locomotive function during their hospital stay and to change patients' life style after discharge in order to keep the patients in the best functional state for the longest time.

Although we inquired about the long-term outcome for many stroke patients, the investigation was restricted to one institution. Therefore, multiinstitution research of locomotive function for stroke patients will be necessary in the future.

\section{REFERENCES}

1) Appelros P, Nydevik I, Seiger A, et al.: Predictors of severe stroke. Influence of pre existing dementia and cardiac disorders. Stroke, 2002, 33: 2357-2362.

2) Daverat P, Castel JP, Dartigues JF, et al.: Death and functional outcome after spontaneous intracerebral hemorrhage: a prospective study of 166 cases using multivariate analysis. Stroke, 1991, 22: 1-6.

3) Fiorelli M, Alperovitch A, Argentino C, et al.: Prediction of long-term outcome in the early hours following acute ischemic stroke. Arch Neurol, 1995, 
52: $250-255$

4) Heinemann AW, Roth EJ, Cichowski K, et al.: Multivariate analysis of improvement and outcome following stroke rehabilitation. Arch Neurol, 1987, 44: 1167-1172.

5) Henon H, Godefroy O, Leys D, et al.: Early predictors of death and disability after acute cerebral ischemic event. Stroke, 1995, 26: 392-398.

6) Matsunaga A, Kurokawa Y, Kanda T, et al.: Prediction of locomotion function at one month after stroke. J Phys Ther Sci, 1997, 9: 93-97.

7) Nakayama H, Jorgensen HS, Raaschou HO, et al.: The influence of age on stroke outcome: The Copenhagen stroke study. Stroke, 1994, 25: 808-813.

8) Stineman MG, Ross R, Maislin G, et al.: Risk of acute hospital transfer and mortality during stroke rehabilitation. Arch Phys Med Rehabili, 2003, 84: 712-718.

9) Tuhrim S, Dambrosia JM, Price TR, et al.: Prediction of intracerebral hemorrhage survival. Ann Neurol, 1988, 24: 258-263.

10) Wade DT, Hewer RL: Stroke: associations with age, sex, and side of weakness. Arch Phys Med Rehabili, 1986, 67: 540-545.

11) Bravata DM, Ho SY, Brass LM, et al.: Long-term mortality in cerebrovascular disease. Stroke, 2003, 34: 699-704.

12) Bronnum-Hansen $H$, Davidsen $M$, Thorvaldsen $P$ : Long-term survival and causes of death after stroke. Stroke, 2001, 32: 2131-2136.

13) Dennis MS, Burn JPS, Sandercock PAG, et al.: Long- term survival after first-ever stroke: The Oxfordshire community stroke project. Stroke, 1993, 24: 796-800.

14) Hankey GJ, Jamrozik K, Broadhurst RJ, et al.: Fiveyear survival after first-ever stroke and related prognostic factors in the Perth community stroke study. Stroke, 2000, 31: 2080-2086.

15) Hankey GJ, Jamrozik K, Broadhurst RJ, et al.: Longterm disability after first-ever stroke and related prognostic factors in the Perth community stroke study, 1989-1990. Stroke, 2002, 33: 1034-1040.

16) Kojima S, Omura T, Wakamatsu W, et al.: Prognosis and disability of stroke patients after 5 years in Akita, Japan. Stroke, 1990, 21: 72-77.

17) Lai SM, Alter M, Friday G, et al.: Prognosis for survival after an initial stroke. Stroke, 1995, 26: 20112015.

18) Sacco RL, Wolf PA, Kannel WB, et al.: Survival and Recurrence following stroke. The Framingham study. Stroke, 1982, 13: 290-295.

19) Scmidt EV, Smirnov VE, Ryabova VS: Results of the seven-year prospective study of stroke patients. Stroke, 1988, 19: 942-949.

20) Appelros P, Nydevik I, Viitanen M: Poor outcome after first-ever stroke. Predictors for death, dependency, and recurrent stroke within the first year. Stroke, 2003, 34: 122-126.

21) Paolucci S, Grasso MG, Antonucci G, et al.: Mobility status after inpatient stroke rehabilitation: 1-year follow-up and prognostic factors. Arch Phys Med Rehabil, 2001, 82: 2-8. 